\title{
A liberal strategy of red blood cell transfusion reduces cardiogenic shock in elderly patients undergoing cardiac surgery
}

Rosana Ely Nakamura, MD, ${ }^{\mathrm{a}}$ Jean-Louis Vincent, PhD, ${ }^{\mathrm{b}}$ Julia Tizue Fukushima, MSc, ${ }^{\mathrm{a}}$

Juliano Pinheiro de Almeida, MD, PhD, ${ }^{a}$ Rafael Alves Franco, MD, ${ }^{a}$ Clarice Lee Park, MD, ${ }^{\mathrm{a}}$

Eduardo Atsushi Osawa, MD, ${ }^{\mathrm{a}}$ Carolina Maria Pinto Silva, MD, ${ }^{\mathrm{a}}$ Jose Otavio Costa Auler, Jr, PhD, ${ }^{\mathrm{a}}$

Giovanni Landoni, $\mathrm{PhD},{ }^{\mathrm{c}}$ Filomena Regina Barbosa Gomes Galas, $\mathrm{PhD},{ }^{\mathrm{a}}$ Roberto Kalil Filho, $\mathrm{PhD},{ }^{\mathrm{d}}$ and Ludhmila Abrahao Hajjar, $\mathrm{PhD}^{\mathrm{a}}$

\begin{abstract}
Objective: The aim of this study was to compare outcomes in patients undergoing cardiac surgery who are aged 60 years or more or less than 60 years after implementation of a restrictive or a liberal transfusion strategy.

Methods: This is a substudy of the Transfusion Requirements After Cardiac Surgery (TRACS) randomized controlled trial. In this subgroup analysis, we separated patients into those aged 60 years or more (elderly) and those aged less than 60 years randomized to a restrictive or a liberal strategy of red blood cell transfusion. The primary outcome was a composite defined as a combination of 30-day all-cause mortality and severe morbidity.
\end{abstract}

Results: Of the 502 patients included in the Transfusion Requirements After Cardiac Surgery study, $260(51.8 \%)$ were aged 60 years or more and 242 $(48.2 \%)$ were aged less than 60 years and were included in this study. The primary end point occurred in $11.9 \%$ of patients in the liberal strategy group and $16.8 \%$ of patients in the restrictive strategy group $(P=.254)$ for those aged 60 years or more and in $6.8 \%$ of patients in the liberal strategy group and $5.6 \%$ of patients in the restrictive strategy group for those aged less than 60 years $(P=.714)$. However, in the older patients, cardiogenic shock was more frequent in patients in the restrictive transfusion group $(12.8 \%$ vs $5.2 \%, P=.031)$. Thirty-day mortality, acute respiratory distress syndrome, and acute renal injury were similar in the restrictive and liberal transfusion groups in both age groups.

Conclusions: Although there was no difference between groups regarding the primary outcome, a restrictive transfusion strategy may result in an increased rate of cardiogenic shock in elderly patients undergoing cardiac surgery compared with a more liberal strategy. Cardiovascular risk of anemia may be more harmful than the risk of blood transfusion in older patients. (J Thorac Cardiovasc Surg 2015;150:1314-20)

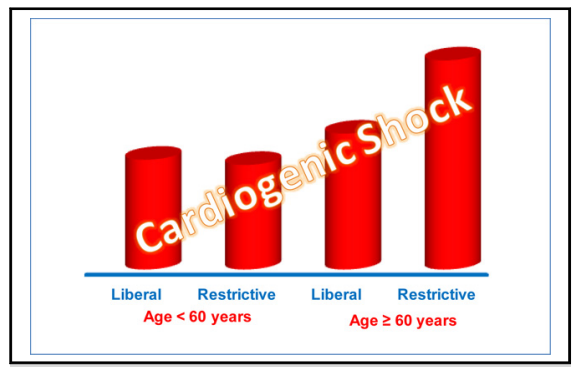

Cardiogenic shock occurs in elderly persons after cardiac surgery when exposed to RBC transfusion. This study illustrates that elderly patients undergoing cardiac surgery, in contrast to younger patients, have a greater risk of cardiogenic shock when exposed to a restrictive strategy of RBC transfusion.

\section{Central Message}

This study aimed to compare clinical outcomes in patients aged 60 years or more or less than 60 years undergoing cardiac surgery and submitted to a restrictive or liberal transfusion strategy. Cardiogenic shock was more frequent in patients in the restrictive transfusion group. There were no differences between groups regarding other severe complications or mortality.

\section{Perspective \\ $\overline{\text { Anemia and RBC transfusions are associated with }}$ worse outcomes after cardiac surgery. Older patients are more exposed to both anemia and transfusion in this setting. Our study is a substudy from the TRACS randomized controlled trial showing that in elderly persons, a restrictive strategy of RBC transfusion is associated with higher rates of cardiogenic shock and its complications. These findings should guide the physician in the decision to administer transfusions to a sick patient at bedside.}

See Editorial Commentary page 1320 .

See Editorial page 1032 .
From the ${ }^{\mathrm{a}}$ Department of Anesthesia and Intensive Care, Heart Institute, University of São Paulo, São Paulo, Brazil; ' ${ }^{b}$ Department of Intensive Care, Erasme Hospital, Universite Libre de Bruxelles, Brussels, Belgium; ${ }^{\mathrm{c}}$ Anesthesiology and Intensive Care, Vita-Salute San Raffaele University, Milan, Italy; and ${ }^{\mathrm{d} D e p a r t m e n t ~ o f ~ C a r d i-~}$ opneumology, Heart Institute, University of São Paulo, São Paulo, Brazil.

This study was sponsored by the University of Sao Paulo, Brazil.

Received for publication Jan 8, 2015; revisions received June 11, 2015; accepted for publication July 18, 2015; available ahead of print Aug 28, 2015.
Address for reprints: Jean-Louis Vincent, $\mathrm{PhD}$, Department of Intensive Care, Erasme University Hospital, Route de Lennik 808, 1070 Brussels, Belgium (E-mail: jlvincen@ulb.ac.be).

$0022-5223 / \$ 36.00$

Copyright (ㄷ 2015 by The American Association for Thoracic Surgery http://dx.doi.org/10.1016/j.jtcvs.2015.07.051 


\section{Abbreviations and Acronyms \\ ICU = intensive care unit \\ $\mathrm{RBC}=$ red blood cell \\ TRACS $=$ Transfusion Requirements After Cardiac Surgery}

Life expectancy is increasing worldwide, and growing numbers of elderly patients are undergoing cardiac surgery. Anemia and red blood cell (RBC) transfusions are both associated with increased morbidity and mortality after cardiac surgery, especially in elderly patients. ${ }^{1,2}$ Recent studies have shown that a restrictive strategy of RBC transfusion is as safe and effective as a liberal one in critically ill patients. ${ }^{3}$ In a recent prospective, randomized clinical trial, Transfusion Requirements After Cardiac Surgery (TRACS), we observed that a restrictive RBC transfusion strategy was as safe as a more liberal approach to transfusion in a diverse group of patients undergoing cardiac surgery. ${ }^{4}$ However, these findings may not apply so readily to elderly patients who have reduced physiologic reserve and more comorbid conditions than younger patients.

A few studies have evaluated clinical outcomes in the elderly according to different strategies of RBC transfusion. ${ }^{5}$ The FOCUS study was a multicenter trial to determine whether a higher threshold for blood transfusion would improve recovery in elderly patients who had undergone surgery for hip fracture. ${ }^{6}$ The inclusion criteria were history of or risk factors for cardiovascular disease. A liberal transfusion strategy (hemoglobin treshold of $10 \mathrm{~g} / \mathrm{dL}$ ), as compared with a restrictive strategy (hemoglobin treshold of $8 \mathrm{~g} / \mathrm{dL}$ ), did not reduce rates of death or inability to walk independently on 60-day follow-up. ${ }^{6}$ In contrast, a recent pilot trial in 110 patients (mean age of 71 years) with acute coronary syndrome or stable angina undergoing cardiac catheterization and with a hemoglobin less than $10 \mathrm{~g} / \mathrm{dL}$ showed a trend for fewer major cardiac events and deaths with a liberal than with a more restrictive $\mathrm{RBC}$ transfusion strategy. ${ }^{7}$ Thus, the risk-benefit profile of RBC transfusions remains uncertain, and more evidence is needed to guide practice in older patients with cardiorespiratory disease, ${ }^{8}$ such as those undergoing cardiac surgery.

Therefore, the aim of this study was to compare outcomes in patients aged 60 years or more or less than 60 years undergoing cardiac surgery after implementation of a restrictive or a liberal transfusion strategy.

\section{MATERIALS AND METHODS}

The TRACS study (ClinicalTrials.gov number NCT01021631) was designed as a prospective, randomized, controlled, noninferiority trial to study blood transfusion thresholds during elective cardiac surgery. ${ }^{4}$ Consecutive adult patients who were scheduled for elective cardiac surgery with cardiopulmonary bypass between February 9, 2009, and February 1, 2010, were enrolled. We excluded patients requiring surgery in an urgency situation; undergoing ascending or descending thoracic aortic procedures; with left ventricular aneurysm resection; unable to receive blood products; who were pregnant; who had cancer, congenital heart defect, hepatic dysfunction, or end-stage renal disease; or who refused consent. The study was approved by the Heart Institute Ethics Committee of the Clinics Hospital, University of Sao Paulo, and written informed consent was obtained from all patients before enrollment. Patients were randomly assigned to be managed according to a liberal (hematocrit values maintained at $\geq 30 \%$ ) or restrictive (hematocrit values maintained at $\geq 24 \%$ ) transfusion strategy from the start of the operation until discharge from the intensive care unit (ICU).

The primary outcome was a composite end point of 30-day all-cause mortality and severe morbidity (cardiogenic shock, acute respiratory distress syndrome, or acute renal injury requiring dialysis or hemofiltration). Cardiogenic shock was defined as the presence of tachycardia, hypotension, and poor perfusion associated with a central venous oxygen saturation less than $65 \%$, a cardiac index $2.2 \mathrm{~L} / \mathrm{min} / \mathrm{m}^{2}$ or less, or the presence of metabolic acidosis (base deficit $>4 \mathrm{mmol} / \mathrm{L}$ ) or an increase in lactate level $(>18.02 \mathrm{mg} / \mathrm{dL})$ in the absence of a cause other than heart failure. ${ }^{9}$ Renal injury was defined according to the Risk, Injury, Failure, Loss of kidney function, and End-stage kidney disease criteria. ${ }^{10}$ Acute respiratory distress syndrome was diagnosed if patients had an acute onset of an inflammatory lung injury characterized by hypoxemia (arterial oxygen tension/inspired oxygen fraction), bilateral infiltrates on chest radiograph, and no clinical evidence of left atrial hypertension. ${ }^{11}$

\section{Statistical Analysis}

In this subgroup analysis, we separated patients into those aged 60 years or more (elderly) and those aged less than 60 years (younger). We compared baseline characteristics, follow-up measures, and clinical outcomes in the 2 age groups on an intention-to-treat basis according to the randomized study group assignment. Continuous variables were compared using a $t$ test or Mann-Whitney $U$ test, and categoric variables were compared using the Pearson chi-square, Fisher exact, or likelihood ratio test. We compared hemoglobin levels between groups using a mixed-design analysis of variance model. We evaluated exposure to

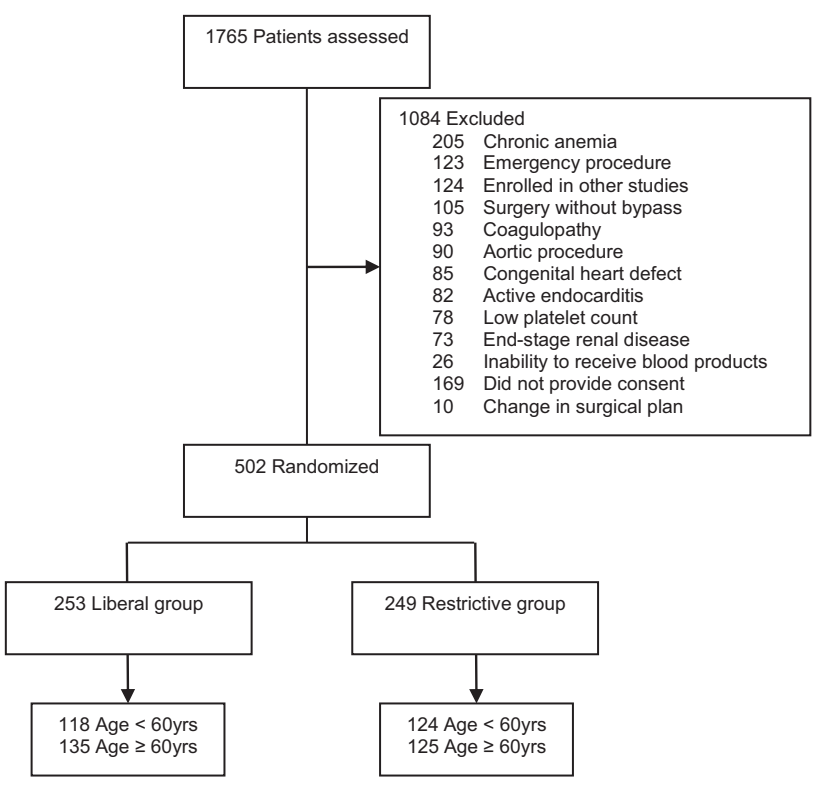

FIGURE 1. Flowchart of the study. 
TABLE 1. Baseline characteristics of study patients

\begin{tabular}{|c|c|c|c|c|c|c|}
\hline \multirow[b]{2}{*}{ Variable } & \multicolumn{2}{|c|}{$<60 \mathrm{y}$} & \multirow[b]{2}{*}{$\boldsymbol{P}$} & \multicolumn{2}{|c|}{$\geq 60 \mathrm{y}$} & \multirow[b]{2}{*}{$\boldsymbol{P}$} \\
\hline & \begin{aligned} & \multicolumn{1}{c}{ Liberal } \\
$\mathrm{n}= & \mathbf{1 1 8}(\mathbf{4 8 . 8} \%)\end{aligned}$ & $\begin{array}{c}\text { Restrictive } \\
\mathrm{n}=124(51.2 \%)\end{array}$ & & $\begin{array}{l}\quad \text { Liberal } \\
\mathbf{n}=\mathbf{1 3 5}(\mathbf{5 1 . 9} \%)\end{array}$ & $\begin{array}{c}\text { Restrictive } \\
\mathrm{n}=125(48.1 \%)\end{array}$ & \\
\hline Age (y) & $51 \pm 10$ & $49 \pm 9$ & .131 & $70 \pm 6$ & $68 \pm 6$ & .129 \\
\hline Sex (male) & 73 (61.9) & $73(58.9)$ & .634 & $88(65.2)$ & $76(60.8)$ & .464 \\
\hline BMI $\left(\mathrm{kg} / \mathrm{m}^{2}\right)$ & $26 \pm 5$ & $26 \pm 5$ & 699 & $26 \pm 4$ & $26 \pm 4$ & .782 \\
\hline \multicolumn{7}{|l|}{ Comorbidities } \\
\hline Arterial hypertension & $84(71.2)$ & $82(66.1)$ & .397 & $117(86.7)$ & $110(88)$ & .747 \\
\hline Diabetes & $22(18.8)$ & $34(27.4)$ & .113 & $57(42.5)$ & $52(41.9)$ & .922 \\
\hline Dyslipidemia & $52(44.4)$ & $66(53.2)$ & .173 & $87(64.4)$ & $81(65.9)$ & .812 \\
\hline Renal disease & $9(7.8)$ & $7(5.8)$ & .533 & $17(12.9)$ & $19(15.3)$ & .574 \\
\hline Smoking & $26(22)$ & $29(23.4)$ & .802 & $8(5.9)$ & $9(7.2)$ & .678 \\
\hline COPD & $5(4.3)$ & $6(4.9)$ & .823 & $1(0.8)$ & $2(1.7)$ & .502 \\
\hline Unstable angina & $34(28.8)$ & $32(25.8)$ & 600 & $45(33.3)$ & $44(35.2)$ & .751 \\
\hline Previous myocardial infarction & $34(28.8)$ & $39(32)$ & .595 & $52(38.5)$ & $50(40.3)$ & .767 \\
\hline Heart failure (NYHA) & & & .847 & & & .108 \\
\hline I & $2(3.1)$ & $1(1.6)$ & & $6(10)$ & $7(13.2)$ & \\
\hline II & $25(38.5)$ & $23(36.5)$ & & $17(28.3)$ & $25(47.2)$ & \\
\hline III & $34(52.3)$ & $33(52.4)$ & & $31(51.7)$ & $16(30.2)$ & \\
\hline IV & $4(6.2)$ & $6(9.5)$ & & $6(10)$ & $5(9.4)$ & \\
\hline Left ventricular ejection fraction & & & .918 & & & .429 \\
\hline$<40$ & $15(12.7)$ & $14(11.3)$ & & $17(12.6)$ & $23(18.4)$ & \\
\hline $40-59$ & $34(28.8)$ & $38(30.6)$ & & $42(31.1)$ & $37(29.6)$ & \\
\hline$>60$ & $69(58.5)$ & $72(58.1)$ & & $76(56.3)$ & $65(52)$ & \\
\hline euroSCORE, median (IQR) & $3(2-6)$ & $3(2-5)$ & .091 & $5(4-7)$ & $5(3-7)$ & .661 \\
\hline Parsonnet, median (IQR) & $8(4-13)$ & $8(5-13)$ & .905 & $14(7-21)$ & $12(6-20)$ & .398 \\
\hline \multicolumn{7}{|l|}{ Preoperative laboratory values } \\
\hline Hemoglobin (g/dL) & $13.2 \pm 1.6$ & $13.6 \pm 1.8$ & .070 & $13.1 \pm 1.6$ & $13.1 \pm 1.8$ & .844 \\
\hline Hematocrit $(\%)$ & $40 \pm 4$ & $40 \pm 5$ & .401 & $39 \pm 4$ & $40 \pm 5$ & .710 \\
\hline Prothrombin time (sec) & $11.1 \pm 1.3$ & $11.3 \pm 2.5$ & .492 & $11 \pm 1.1$ & $11.1 \pm 1.2$ & .707 \\
\hline Platelet count $\left(1000 / \mathrm{mm}^{3}\right)$ & $222 \pm 70$ & $230 \pm 66$ & .391 & $222 \pm 65$ & $220 \pm 65$ & .809 \\
\hline Creatinine concentration (mg/dL) & $1.1 \pm 0.4$ & $1 \pm 0.3$ & .547 & $1.2 \pm 0.3$ & $1.2 \pm 0.4$ & .479 \\
\hline Leukocyte count $\left(1000 / \mathrm{mm}^{3}\right)$ & $7.4 \pm 1.9$ & $7.8 \pm 2.1$ & .166 & $7.7 \pm 2.2$ & $7.6 \pm 2$ & .575 \\
\hline \multicolumn{7}{|l|}{ Preoperative drug exposure } \\
\hline Aspirin & $39(33.1)$ & $41(33.3)$ & .963 & $64(47.4)$ & $53(42.4)$ & .417 \\
\hline Heparin & $2(1.7)$ & $0(0)$ & .239 & $1(0.7)$ & $2(1.6)$ & .610 \\
\hline
\end{tabular}

Parsonnet is the predictive score for acquired adult heart surgery; System of Units conversion factor: to convert creatinine values to $\mu$ mol/L, multiply by 88.4 . BMI, Body mass index; COPD, chronic obstructive pulmonary disease; NYHA, New York Heart Association; euroSCORE, European System for Cardiac Operative Risk Evaluation; IQR, interquartile range.

RBC transfusion through a logistic regression model for repeated measures.

Results are expressed as means with standard deviation or medians with interquartile ranges (IQRs). Statistical analyses were performed using SPSS version 18.0 (SPSS Inc, Chicago, Ill).

\section{RESULTS}

\section{Study Population}

A total of 1765 patients were assessed for eligibility in the TRACS study (Figure 1). After exclusions for various medical reasons and lack of consent, 512 patients were enrolled in the study: 257 assigned to the liberal group and 255 assigned to the restrictive transfusion strategy group. Of the 502 patients included in the TRACS study, $260(51.8 \%)$ were aged 60 years or more and 242 $(48.2 \%)$ were aged less than 60 years (Figure 1).
Baseline characteristics were well balanced between the strategies of treatment in the 2 age strata (Table 1). Procedure-related variables in the intraoperative period were also similar with the exception of RBC transfusion (Table 2).

In the elderly patients, $70 \%$ in the liberal strategy group received an intraoperative transfusion compared with $44 \%$ in the restrictive group $(P<.001)$, and hemoglobin concentrations were significantly higher in the liberal than in the restrictive strategy group intraoperatively (Figure 2). In the younger patients, $68 \%$ of patients in the liberal strategy group and $36 \%$ of patients in the restrictive group received an intraoperative transfusion $(P<.001)$. Hematocrit concentrations were maintained at or above the threshold for $95 \%$ of the time. Most transfusions were given in the operating room and in the first 3 days after 
TABLE 2. Intraoperative data in the restrictive and liberal strategy groups

\begin{tabular}{|c|c|c|c|c|c|c|}
\hline \multirow[b]{2}{*}{ Variable } & \multicolumn{2}{|c|}{ Age $<60$ y } & \multirow[b]{2}{*}{$\boldsymbol{P}$} & \multicolumn{2}{|c|}{ Age $\geq 60 y$} & \multirow[b]{2}{*}{$P$} \\
\hline & $\begin{aligned} & \text { Liberal } \\
\mathrm{n}= & \mathbf{1 3 5}(51.9 \%)\end{aligned}$ & $\begin{array}{c}\text { Restrictive } \\
\mathrm{n}=125(48.1 \%)\end{array}$ & & $\begin{aligned} & \text { Liberal } \\
\mathrm{n}= & \mathbf{1 3 5}(\mathbf{5 1 . 9} \%)\end{aligned}$ & $\begin{array}{c}\text { Restrictive } \\
\mathrm{n}=125(48.1 \%)\end{array}$ & \\
\hline Procedure & & & .389 & & & .387 \\
\hline CABG & $62(52.5)$ & $68(54.8)$ & & $93(68.9)$ & $84(67.2)$ & \\
\hline Valve replacement & $53(44.9)$ & $49(39.5)$ & & $26(19.3)$ & $31(24.8)$ & \\
\hline $\mathrm{CABG}+$ valve & $3(2.5)$ & $7(5.6)$ & & $16(11.9)$ & $10(8.0)$ & \\
\hline Number of grafts per patient & & & .716 & & & 647 \\
\hline 1 & $3(4.6)$ & $6(8)$ & & $13(11.9)$ & $10(10.6)$ & \\
\hline 2 & $20(30.8)$ & $22(29.3)$ & & $33(30.3)$ & $24(25.5)$ & \\
\hline 3 & $26(40)$ & $32(42.7)$ & & $41(37.6)$ & $45(47.9)$ & \\
\hline 4 & $13(20)$ & $14(18.7)$ & & $19(17.4)$ & $12(12.8)$ & \\
\hline$>4$ & $3(4.6)$ & $1(1.3)$ & & $3(2.8)$ & $3(3.2)$ & \\
\hline $\begin{array}{l}\text { Cardiopulmonary bypass } \\
\text { duration (min), median (IQR) }\end{array}$ & $90(75-113)$ & $90(70-114)$ & .536 & $88(70-108)$ & $94(79-111)$ & .057 \\
\hline Initial hemoglobin $(\mathrm{mg} / \mathrm{dL})$ & $12.7 \pm 1.7$ & $12.8 \pm 1.8$ & .633 & $12.3 \pm 1.6$ & $12.6 \pm 1.8$ & .208 \\
\hline Final hemoglobin (mg/dL) & $10.8 \pm 1.3$ & $10.3 \pm 1.7$ & .009 & $10.4 \pm 1.2$ & $9.9 \pm 1.2$ & .001 \\
\hline Initial hematocrit (mg/dL) & $39 \pm 5.2$ & $39.4 \pm 5.4$ & .603 & $38 \pm 5$ & $39 \pm 5$ & .228 \\
\hline Final hematocrit (mg/dL) & $33 \pm 4$ & $32 \pm 5$ & .007 & $32 \pm 4$ & $30 \pm 4$ & $<.001$ \\
\hline Initial lactate $(\mathrm{mmol} / \mathrm{L})$ & $16 \pm 17$ & $14 \pm 5$ & .172 & $14 \pm 5$ & $15 \pm 5$ & .349 \\
\hline Final lactate $(\mathrm{mmol} / \mathrm{L})$ & $38 \pm 26$ & $35 \pm 22$ & .282 & $36 \pm 22$ & $37 \pm 21$ & .709 \\
\hline Initial $\mathrm{SvcO}_{2}(\%)$ & $74 \pm 8$ & $74 \pm 9$ & .839 & $73 \pm 8$ & $74 \pm 9$ & .708 \\
\hline Final $\mathrm{SvcO}_{2}(\%)$ & $82 \pm 7$ & $81 \pm 9$ & .340 & $80 \pm 8$ & $81 \pm 7$ & .395 \\
\hline Administered fluids (L), median (IQR) & $3.0(2.0-3.5)$ & $3.0(2.5-3.5)$ & .120 & $3.0(2.5-3.5)$ & $3.0(2.5-3.5)$ & .110 \\
\hline Crystalloids (L), median (IQR) & $2.5(2.0-3.0)$ & $2.5(2.5-3.0)$ & .401 & $2.5(2.0-3.0)$ & $3.0(2.5-3.0)$ & .189 \\
\hline Albumin & $1(0.8)$ & $1(0.8)$ & 1.000 & $1(0.7)$ & $1(0.8)$ & 1.000 \\
\hline Hydroxyethyl starch $6 \%(130 / 0.4)$ & $43(36.4)$ & $57(46)$ & .152 & $57(42.2)$ & $60(48)$ & .349 \\
\hline Intraoperative transfusion & $79(67.5)$ & $45(36.3)$ & $<.001$ & $95(70.4)$ & $55(44)$ & $<.001$ \\
\hline Units of transfused RBCs & & & $<.001$ & & & $<.001$ \\
\hline 0 & $30(25.4)$ & $71(57.3)$ & & $25(18.5)$ & $60(48)$ & \\
\hline 1 & $25(21.2)$ & $25(20.2)$ & & $16(11.9)$ & $19(15.2)$ & \\
\hline 2 & $26(22)$ & $16(12.9)$ & & $37(27.4)$ & 27 (21.6) & \\
\hline 3 & $12(10.2)$ & $3(2.4)$ & & $25(18.5)$ & $11(8.8)$ & \\
\hline 4 & $12(10.2)$ & $4(3.2)$ & & $13(9.6)$ & $4(3.2)$ & \\
\hline$>4$ & $13(11)$ & $5(4)$ & & $19(14.1)$ & $4(3.2)$ & \\
\hline
\end{tabular}

Initial = samples collected after the induction of anesthesia; final = samples collected at the end of surgery. $C A B G$, Coronary artery bypass grafting; $I Q R$, interquartile range $\mathrm{SvcO}_{2}$, central venous oxygen saturation; $\mathrm{RBC}$, red blood cell.

surgery, and the liberal strategy group was more exposed to RBC transfusion over time (Figure 3). There was no difference in the median storage time of RBC units between the liberal strategy and the restrictive strategy (2 days [1-2] vs 2 days [2-3], $P=.051$ ).

\section{Outcome Measures}

The primary end point occurred in $11.9 \%$ of patients in the liberal strategy group and $16.8 \%$ of patients in the restrictive strategy group $(P=.254)$ for those aged 60 years or more and in $6.8 \%$ of patients in the liberal strategy group and $5.6 \%$ of patients in the restrictive strategy group for those aged less than 60 years $(P=.714)$ (Table 3$)$. Thirty-day mortality, acute respiratory distress syndrome, and acute renal injury were similar in the restrictive and liberal transfusion groups in both age groups. The incidence of cardiogenic shock was similar in the restrictive and liberal transfusion groups for patients aged less than 60 years $(4.8 \%$ vs $4.2 \%, P=.822)$. However, in the older patients, cardiogenic shock was more frequent in patients in the restrictive transfusion group $(12.8 \%$ vs $5.2 \%, P=.031)$ (Table 3).

Patients who had cardiogenic shock compared with patients without shock needed more dobutamine $(100 \%$ vs $60 \%, P<.001)$ and norepinephrine $(32.4 \%$ vs $15.4 \%$, $P=.01)$, and presented a higher rate of mechanical ventilation over 48 hours $(32.4 \%$ vs $15.4 \%, P=.01)$. Older patients who presented cardiogenic shock had a more severe presentation of this disease compared with patients aged less than 60 years, lasting 57 hours (IQR, 22-114) versus 34 hours (IQR, 13-75) $(P<.0003)$, resulting in a higher incidence of acute kidney injury (requiring renal replacement therapy) $(13 \%$ vs $5 \%, P=.03)$ and a greater length of hospital (13 days [10-20] vs 10 days [8-12], 

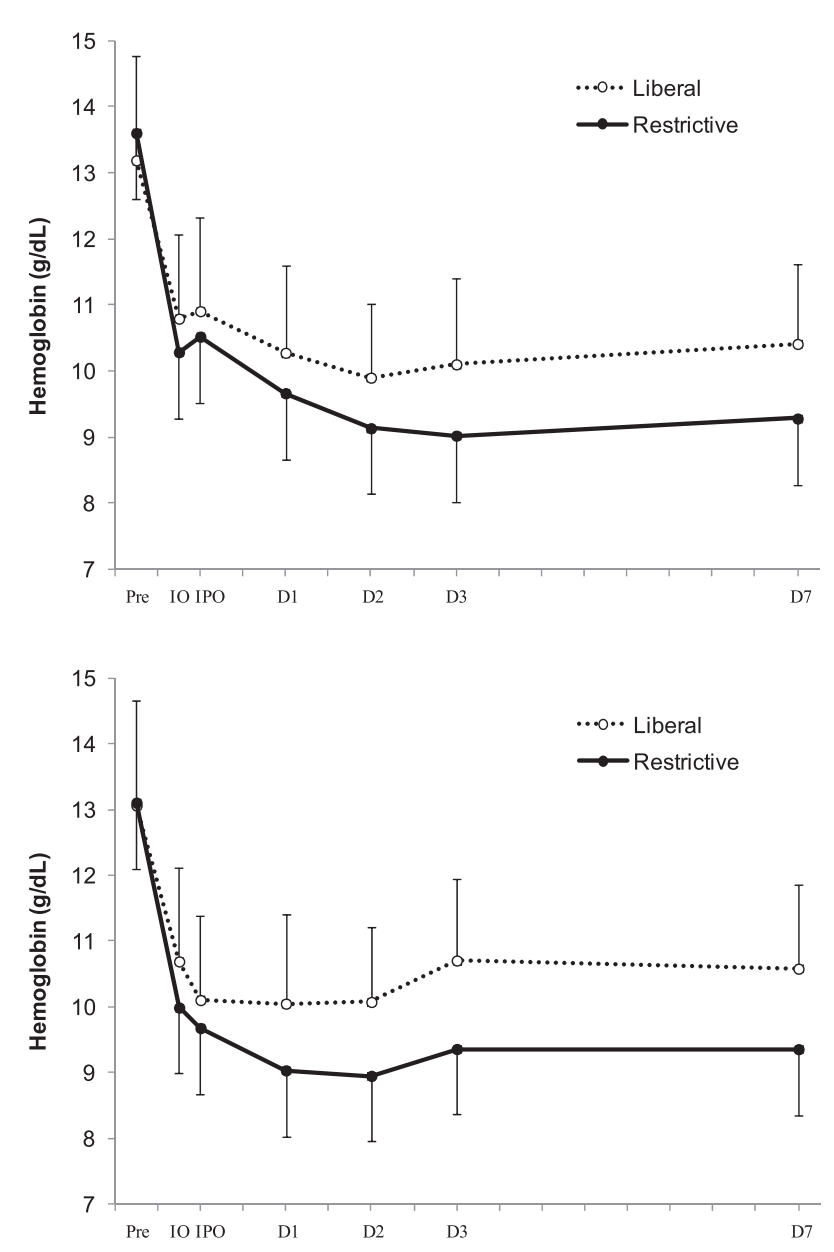

FIGURE 2. Mean hemoglobin levels during the study in patients aged less than 60 years (top) and patients aged 60 years or more (bottom) according to transfusion strategy. $I O$, Intraoperative period; $I P O$, immediate postoperative period. D1-D7 indicate postoperative days. $P<.05$.

$P=.0001)$ and ICU stay (6 days [4-9] vs 5 days [4-7], $P=.0001)$. There were no differences between groups in the occurrence of acute kidney injury, in the duration of mechanical ventilation, and in delirium.

\section{DISCUSSION}

In this subgroup analysis of the TRACS study, a restrictive strategy of RBC transfusion was independently associated with a 2.5 -fold higher rate of cardiogenic shock after cardiac surgery. These data suggest that a restrictive transfusion strategy targeting a hematocrit of $24 \%$, as recommended in recent studies and guidelines, ${ }^{7,12,13}$ may be less safe than a more liberal strategy, targeting a hematocrit of $30 \%$, in terms of cardiovascular risk in patients aged 60 years or more.

The rationale for implementing a restrictive transfusion strategy is based on many studies that have shown a lack of benefit and substantially increased costs and adverse effects associated with RBC transfusion. ${ }^{14-20}$ These adverse effects include acute hemolytic and nonhemolytic reactions,
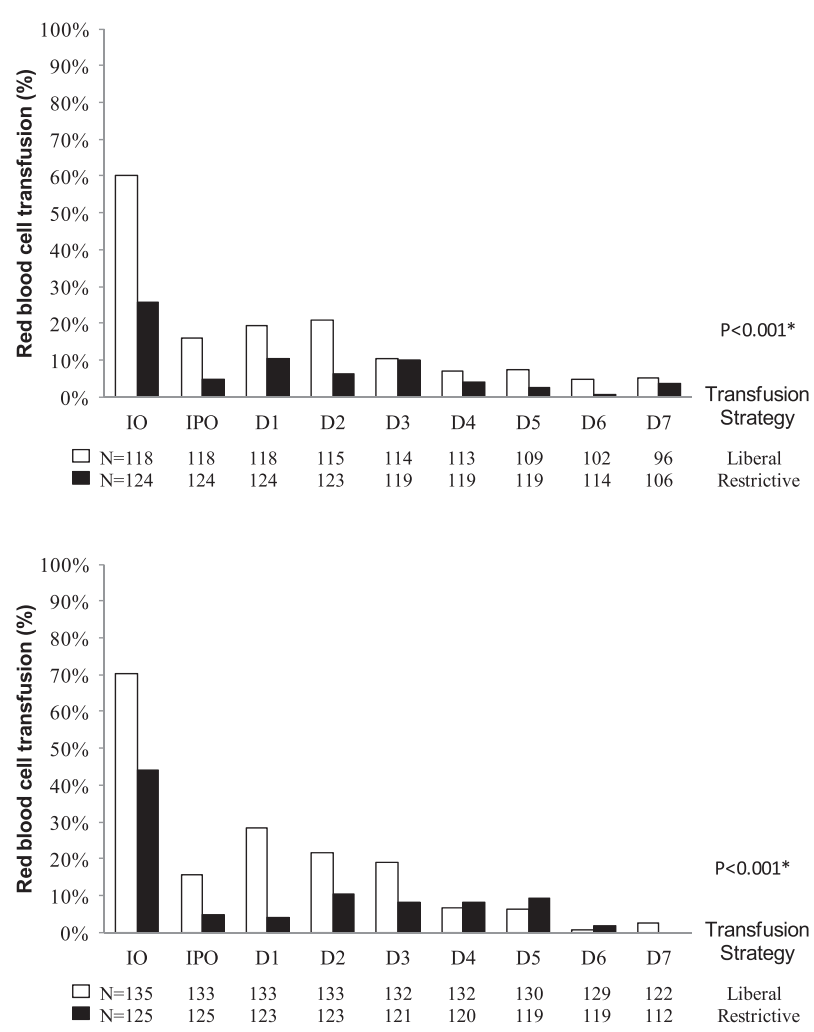

FIGURE 3. Percentage of patients aged less than 60 years (top) and patients aged 60 years or more (bottom) who received an RBC transfusion in the liberal and restrictive strategy groups. $I O$, Intraoperative period; $I P O$, immediate postoperative period. D1-D7 indicate days after ICU admission. $* P<.05$ (comparison between groups - logistic regression for repeated measures).

transmission of viral and bacterial diseases, transfusionrelated acute lung injury, and transfusion-associated circulatory overload. Nevertheless, there is concern about the possible increased risk of adverse effects of anemia in patients with cardiovascular disease. ${ }^{21,22}$ One retrospective cohort study of 1958 surgical patients reported that increased severity of anemia was associated with a significant increase in mortality rates among patients with cardiovascular disease. ${ }^{21}$ Moreover, some studies in patients with anemia and myocardial infarction seem to suggest that transfusion may be beneficial, particularly for patients aged more than 65 years. ${ }^{23,24}$ A recent pilot study by Carson and colleagues $^{7}$ showed that a restrictive transfusion strategy in older patients with symptomatic coronary disease may result in a higher rate of major cardiovascular complications. In our study, patients aged 60 years or more had an increased risk of cardiogenic shock when a hematocrit threshold of $24 \%$ was used compared with a threshold of $30 \%$. Older patients may have reduced compensatory mechanisms after surgical trauma, making them more likely to develop mismatch between oxygen delivery and consumption and thus tissue hypoxia, and optimizing cardiac output and arterial oxygen content during cardiac surgery may reduce cardiovascular 
TABLE 3. Incidence of the primary end point-composite of 30-day all-cause mortality and severe morbidity (cardiogenic shock, acute respiratory distress syndrome, or acute renal injury requiring dialysis or hemofiltration)—and its individual components according to transfusion strategy in the 2 age groups

\begin{tabular}{|c|c|c|c|c|c|c|}
\hline \multirow[b]{2}{*}{ End point } & \multicolumn{2}{|c|}{ Age $<60$ y } & \multirow[b]{2}{*}{$\boldsymbol{P}$} & \multicolumn{2}{|c|}{ Age $\geq 60 y$} & \multirow[b]{2}{*}{$\boldsymbol{P}$} \\
\hline & Liberal n (\%) & Restrictive n (\%) & & Liberal n (\%) & Restrictive n (\%) & \\
\hline Primary composite end point & $8(6.8)$ & $7(5.6)$ & .71 & $16(11.9)$ & $21(16.8)$ & .25 \\
\hline 30-d mortality & $5(4.2)$ & $5(4.0)$ & 1.00 & $7(5.2)$ & $10(8.0)$ & .35 \\
\hline Cardiogenic shock & $5(4.2)$ & $6(4.8)$ & .82 & $7(5.2)$ & $16(12.8)$ & .03 \\
\hline ARDS & $2(1.7)$ & $2(1.6)$ & 1.00 & $0(0)$ & $3(2.4)$ & .11 \\
\hline Acute renal injury requiring RRT & $3(2.5)$ & $4(3.2)$ & 1.00 & $10(7.4)$ & $6(4.8)$ & .38 \\
\hline
\end{tabular}

$A R D S$, Acute respiratory distress syndrome; $R R T$, renal replacement therapy.

complications. In our study, older patients who had cardiogenic shock had a more severe presentation of the disease, resulting in a higher incidence of acute kidney injury requiring renal replacement therapy, prolonged mechanical ventilation, and a longer ICU and hospital length of stay.

\section{Study Limitations}

Although there was a significant difference favoring the liberal arm, these data should be interpreted in the light of several study limitations. The study was single center, limiting its generalizability to other units and countries. Patients in this study experienced slightly higher rates of serious complications than those in other studies, likely because our population was a relatively high-risk group, with a median European System for Cardiac Operative Risk Evaluation of 5, and our results may not be relevant in patients with lower disease severity. Also, the sample size is small and our conclusions are based on a limited number of events. Moreover, these are results from a substudy, although this analysis was defined a priori. Future studies are needed to better characterize the outcomes of different strategies of transfusion in an older adult population undergoing cardiac surgery. Also, these should include assessments of frailty and markers of increased vulnerability to improve our understanding of this specific population.

\section{CONCLUSIONS}

Despite these limitations, a restrictive transfusion strategy resulted in an increased rate of cardiogenic shock in elderly patients undergoing cardiac surgery compared with a more liberal strategy, suggesting that in this specific population, the cardiovascular risk of anemia may be more harmful than the risk of blood transfusion..$^{25,26}$

\section{Conflict of Interest Statement}

Authors have nothing to disclose with regard to commercial support.

\section{References}

1. Ranucci M, Baryshnikova E, Castelvecchio S, Pelissero G. Major bleeding, transfusions, and anemia: the deadly triad of cardiac surgery. Ann Thorac Surg. 2013;96:478-85.
2. Carrascal Y, Maroto L, Rey J, Arevalo A, Arroyo J, Echevarria JR, et al. Impact of preoperative anemia on cardiac surgery in octogenarians. Interact Cardiovasc Thorac Surg. 2010;10:249-55.

3. Carson JL, Carless PA, Hebert PC. Outcomes using lower vs higher hemoglobin thresholds for red blood cell transfusion. JAMA. 2013:309:83-4.

4. Hajjar LA, Vincent JL, Galas FR, Nakamura RE, Silva CM, Santos MH, et al. Transfusion requirements after cardiac surgery: the TRACS randomized controlled trial. JAMA. 2010;304:1559-67.

5. Ad N, Massimiano PS, Burton NA, Halpin L, Pritchard G, Shuman DJ, et al. Effect of patient age on blood product transfusion after cardiac surgery. J Thorac Cardiovasc Surg. 2015;150:209-14.

6. Carson JL, Terrin ML, Noveck H, Sanders DW, Chaitman BR, Rhoads GG, et al Liberal or restrictive transfusion in high-risk patients after hip surgery. $N$ Engl $J$ Med. 2011;365:2453-62.

7. Carson JL, Brooks MM, Abbott JD, Chaitman B, Kelsey SF, Triulzi DJ, et al. Liberal versus restrictive transfusion thresholds for patients with symptomatic coronary artery disease. Am Heart J. 2013;165:964-71.e1.

8. Carson JL, Grossman BJ, Kleinman S, Tinmouth AT, Marques MB, Fung MK, et al. Red blood cell transfusion: a clinical practice guideline from the AABB*. Ann Intern Med. 2012;157:49-58.

9. Masse L, Antonacci M. Low cardiac output syndrome: identification and management. Crit Care Nurs Clin North Am. 2005;17:375-83.

10. Haase M, Bellomo R, Matalanis G, Calzavacca P, Dragun D, Haase-Fielitz A. A comparison of the RIFLE and Acute Kidney Injury Network classifications for cardiac surgery-associated acute kidney injury: a prospective cohort study. $J$ Thorac Cardiovasc Surg. 2009;138:1370-6.

11. Bernard GR, Artigas A, Brigham KL, Carlet J, Falke K, Hudson L, et al. The American-European Consensus Conference on ARDS. Definitions, mechanisms, relevant outcomes, and clinical trial coordination. Am J Respir Crit Care Med. 1994;149:818-24.

12. Ferraris VA, Ferraris SP, Saha SP, Hessel EA 2nd, Haan CK, Royston BD, et al. Perioperative blood transfusion and blood conservation in cardiac surgery: the Society of Thoracic Surgeons and The Society of Cardiovascular Anesthesiologists clinical practice guideline. Ann Thorac Surg. 2007;83: S27-86.

13. American Society of Anesthesiologists Task Force on Perioperative Blood Transfusion and Adjuvant Therapies. Practice guidelines for perioperative blood transfusion and adjuvant therapies: an updated report by the American Society of Anesthesiologists Task Force on Perioperative Blood Transfusion and Adjuvant Therapies. Anesthesiology. 2006;105: 198-208.

14. Reeves BC, Murphy GJ. Increased mortality, morbidity, and cost associated with red blood cell transfusion after cardiac surgery. Curr Opin Cardiol. 2008;23: 607-12.

15. Murphy GJ, Reeves BC, Rogers CA, Rizvi SI, Culliford L, Angelini GD Increased mortality, postoperative morbidity, and cost after red blood cell transfusion in patients having cardiac surgery. Circulation. 2007;116: 2544-52.

16. Scott BH, Seifert FC, Grimson R. Blood transfusion is associated with increased resource utilisation, morbidity and mortality in cardiac surgery. Ann Card Anaesth. 2008;11:15-9.

17. Shaw RE, Johnson CK, Ferrari G, Zapolanski A, Brizzio M, Rioux N, et al Balancing the benefits and risks of blood transfusions in patients undergoing cardiac surgery: a propensity-matched analysis. Interact Cardiovasc Thorac Surg. 2013;17:96-102. 
18. Shaw RE, Johnson CK, Ferrari G, Brizzio ME, Sayles K, Rioux N, et al. Blood transfusion in cardiac surgery does increase the risk of 5-year mortality: results from a contemporary series of 1714 propensity-matched patients. Transfusion. 2014;54:1106-13.

19. Galas FR, Almeida JP, Fukushima JT, Osawa EA, Nakamura RE, Silva CM, et al. Blood transfusion in cardiac surgery is a risk factor for increased hospital length of stay in adult patients. J Cardiothorac Surg. 2013;8:54.

20. LaPar DJ, Crosby IK, Ailawadi G, Ad N, Choi E, Spiess BD, et al. Blood product conservation is associated with improved outcomes and reduced costs after cardiac surgery. J Thorac Cardiovasc Surg. 2013;145: 796-803.

21. Carson JL, Duff A, Poses RM, Berlin JA, Spence RK, Trout R, et al. Effect of anaemia and cardiovascular disease on surgical mortality and morbidity. Lancet. 1996;348:1055-60

22. DeFoe GR, Ross CS, Olmstead EM, Surgenor SD, Fillinger MP, Groom RC, et al. Lowest hematocrit on bypass and adverse outcomes associated with coronary artery bypass grafting. Northern New England Cardiovascular Disease Study Group. Ann Thorac Surg. 2001;71:769-76.

23. Sabatine MS, Morrow DA, Giugliano RP, Burton PB, Murphy SA, McCabe CH, et al. Association of hemoglobin levels with clinical outcomes in acute coronary syndromes. Circulation. 2005;111:2042-9.

24. Wu WC, Rathore SS, Wang Y, Radford MJ, Krumholz HM. Blood transfusion in elderly patients with acute myocardial infarction. N Engl J Med. 2001;345: 1230-6.

25. Vincent JL, Hajjar LA. What's new in transfusion policies? Intensive Care Med. 2013;39:1002-4.

26. Vincent JL. Indications for blood transfusions: too complex to base on a single number? Ann Intern Med. 2012;157:71-2.

Key Words: red blood cell transfusion, cardiogenic shock, elderly, cardiac surgery

\title{
EDITORIAL COMMENTARY
}

\section{Transfusion strategies in cardiac surgery: More pieces to the puzzle, more questions to be answered}

\author{
Juan N. Pulido, MD
}

From the Divisions of Cardiovascular Anesthesiology and Critical Care Medicine, Department of Anesthesiology, Mayo Clinic Rochester, Rochester, Minn.

Disclosures: Author has nothing to disclose with regard to commercial support.

Received for publication Aug 11, 2015; accepted for publication Aug 11, 2015; available ahead of print Sept 6, 2015.

Address for reprints: Juan N. Pulido, MD, Divisions of Cardiovascular Anesthesiology and Critical Care Medicine, Mayo Clinic Rochester, 200 1st St SW, Mary Brigh Building, Rochester, MN 55905 (E-mail: pulido. juan@mayo.edu).

J Thorac Cardiovasc Surg 2015;150:1320-1

$0022-5223 / \$ 36.00$

Copyright $(\underset{2}{ } 2015$ by The American Association for Thoracic Surgery

http://dx.doi.org/10.1016/j.jtcvs.2015.08.040

Blood management has emerged as an important aspect of perioperative cardiac surgical care and has evolved to become a key quality indicator. ${ }^{1}$ Despite growing evidence of the risks and cost of blood transfusion, along with the physiologic rationale of improvement of oxygen delivery to tissues during hemorrhage and ischemia, the jury still out with respect to the optimal hemoglobin trigger for red blood cell transfusion in cardiac surgical patients, specifically in elderly patients, and how we define the concept of physiologic reserve, possibly to modify the transfusion threshold.

It is important, however, to recognize, that both anemia and transfusion are associated with poor outcomes and that both of these conditions are common among cardiac surgical patients. These patients frequently are seen with a myriad of comorbidities in different states of compensation and physiologic reserve that are difficult to control

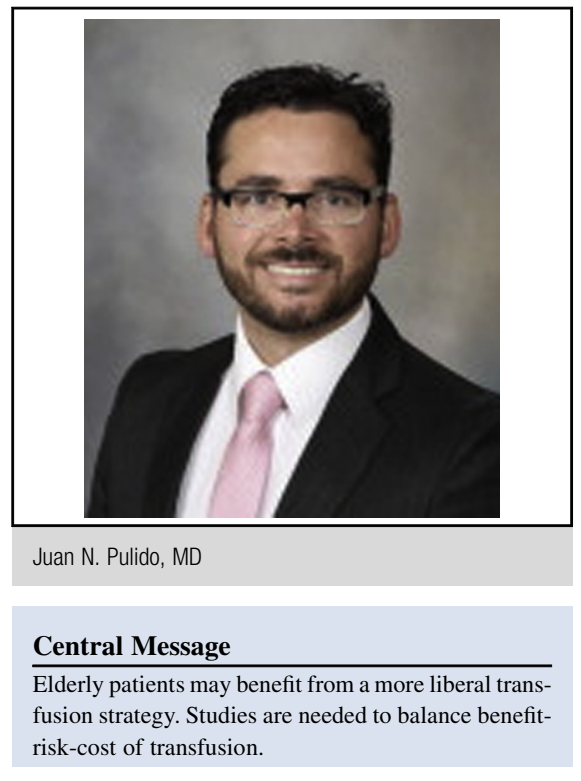

See Article page 1314.

See Editorial page 1032.

for in large-scale studies. Moreover, the variability of the hemoglobin value in the perioperative care episode, as well as the frequency of rapid changes in blood volume during this period, make the issue of transfusion "trigger" 